\title{
Erratum to: Reduced length of stay in radical cystectomy patients with oral versus parenteral post-operative nutrition protocol
}

Peter Declercq $^{1,2} \cdot$ Gunter De Win $^{3,4,5}$ - Frank Van der $\mathrm{Aa}^{3,4}$ - Elodie Beels ${ }^{3,4}$. Lorenz Van der Linden ${ }^{1,2} \cdot$ Hendrik Van Poppel ${ }^{3,4} \cdot$ Ludo Willems $^{1,2}$.

Isabel Spriet ${ }^{1,2}$

Published online: 17 March 2015

(C) Koninklijke Nederlandse Maatschappij ter bevordering der Pharmacie 2015

\section{Erratum to: Int J Clin Pharm}

DOI 10.1007/s11096-015-0072-9

Unfortunately, the first and the last name of the fourth, seventh and eighth co-authors were published incorrectly in the original publication. The corrected author names are given in the erratum.

The online version of the original article can be found under doi:10.1007/s11096-015-0072-9.

Peter Declercq

peter.declercq@uzleuven.be

1 Pharmacy Department, University Hospitals Leuven,

Herestraat 49, 3000 Leuven, Belgium

2 Department of Pharmaceutical and Pharmacological

Sciences, KU Leuven, Leuven, Belgium

3 Department of Urology, Faculty of Medicine, University Hospitals Leuven, Leuven, Belgium

4 Department Development and Regeneration, KU Leuven, Leuven, Belgium

5 Department of Urology, Faculty of Medicine, University Hospital Antwerp, Antwerp, Belgium 